\title{
Hemihidrosis Due to Skin Pressure with Particular Remarks on the Intensity and Area of the Pressure Stimuli
}

\author{
Eiko Tadaki, Takao Kumazawa, Kazue Mizumura, \\ and Kentaro TAKAGI \\ Department of Physiology, School of Medicine, \\ Nagoya University, Nagoya, 466 Japan
}

\begin{abstract}
Sweating of symmetrical areas of the torso was measured by means of both the filter paper method and electrohygrometric method. Spontaneous sweating rates of the left and right side of the upper and lower chest and the back were statistically highly correlated. Reduction of sweating by pressure application to the unilateral subaxillary region ("pressure hemihidrosis") was studied quantitatively with 12 combinations of pressure stimuli, i.e., 1, 2, 3 and $4 \mathrm{~kg}$ weights applied to disks with a surface area of 2,6 and $16.6 \mathrm{~cm}^{2}$, respectively. The amount of reduction in sweating rate was proportional to both the intensity and the surface area of pressure applied. It was revealed that hemihidrotic effects induced from the unit area of pressure stimulation was statistically highly correlated to the pressure intensity.
\end{abstract}

Hemihidrosis induced by postural changes was first described by KuNO (1934). This phenomenon was proved to be induced by a unilateral skin pressure due to one's own body weight, and was called "pressure hemihidrosis" (TAKAGI and SAKURAI, 1950). WATKINS (1956) argued, however, that this phenomenon was observed by chance as a spontaneous difference in sweating rates on symmetrical areas of the body surface. Using a human centrifuge, FERRES (1960) confirmed a marked hemihidrosis caused by pressure, although she failed to observe hemihidrotic response on application of $5 \mathrm{~kg}$ over a broad area of one side of the chest. Presumably this is due to an insufficient intensity of pressure.

As was reviewed by TAKAGI and KoBAYASI (1955), a number of works reported on pressure effects on various autonomic functions including "pressure hemihidrosis," but a quantitative relationship between pressure stimuli and their effects has not been studied systematically. It is conceivable that the effects reflexly caused by skin pressure depend on both the intensity and area of the pressure stimulation applied.

In the present work, "pressure-hemihidrosis" was quantitatively studied, particularly in relation to the intensity and area of the stimuli. A preliminary

Received for publication August 29, 1980

只木英子，熊澤孝朗，水村和枝，高木健太郎 
account of this work was presented in 1977 (TADAKI et al.).

\section{METHODS}

Four healthy men (aged 21 to 45 years) and 19 healthy women (aged 20 to 21 years) acted as subjects. The purpose of this study and the experimental procedures were explained to the subjects before their voluntary consent was obtained.

The rate of sweating was measured either by the filter paper method or by the electrohygrometric method devised by NaKaYAMA and TAKagi (1959). For the filter paper method, a shallow acrylic cylinder with a cross-sectional area of $20 \mathrm{~cm}^{2}$ was attached to the skin by adhesive. The sweat on the skin inside the cylinder was absorbed by layers of filter paper held in contact with the skin by a well-fitting lid, which minimized evaporation of the sweat. The sweat for $10 \mathrm{~min}$ was collected and the filter papers were weighed in weighing bottles just after each collection. To minimize the difference of the collecting period, 2 well-trained persons collected each paired filter paper simultaneously by order of a third person. In the electrohygrometric method, changes in moisture of the air passing through a hemispheric capsule $\left(20 \mathrm{~cm}^{2}\right)$ attached to the skin are continuously measured by an electrohygrometer and recorded on an ink-writing oscillograph. The amount of sweat in a certain period was calculated by measuring the area surrounded by the baseline and the sweating curve with a planimeter or by weighing the traced area of the record, and was expressed in $\mathrm{mg} / 20 \mathrm{~cm}^{2} \cdot \mathrm{min}$.

Sweating rates of the following 3 pairs of symmetrical areas of the torso were measured by the filter paper method: 1) the upper chest: the second intercostal space at the mammillary line on the anterior chest, 2) the lower chest: the tenth intercostal space at the mammillary line, 3) the back: the second intercostal space $4 \mathrm{~cm}$ lateral from the midline of the back. The electrohygrometric recordings were made on area 1 ).

Pressure was applied for $1 \mathrm{~min}$ to the unilateral subaxillary region. A hard rubber disk was pressed onto the region by pulling it with a weight via a pully from the other side of the body. Combinations of 4 different weights $(1,2,3$ or

Table 1. Intensities $\left(\mathrm{kg} / \mathrm{cm}^{2}\right)$ of 12 pressure stimuli used.

\begin{tabular}{cccc} 
Weight $(\mathrm{kg})$ & $\begin{array}{c}\mathrm{A} \\
\left(2 \mathrm{~cm}^{2}\right)\end{array}$ & $\begin{array}{c}\mathrm{B} \\
\left(6 \mathrm{~cm}^{2}\right)\end{array}$ & $\begin{array}{c}\mathrm{C} \\
\left(16.6 \mathrm{~cm}^{2}\right)\end{array}$ \\
\hline 1 & 0.50 & 0.17 & 0.06 \\
2 & 1.00 & 0.33 & 0.12 \\
3 & 1.50 & 0.50 & 0.18 \\
4 & 2.00 & 0.67 & 0.24 \\
\hline
\end{tabular}

Pressure application was performed with 12 combinations of weights $(1,2,3$ and $4 \mathrm{~kg})$ and areas $\left(2,6\right.$ and $\left.16.6 \mathrm{~cm}^{2}\right)$ to examine the hemihidrotic response. Numbers in the table indicate the pressure intensity in $\mathrm{kg} / \mathrm{cm}^{2}$. 
$4 \mathrm{~kg}$ ) and a circular disk of 3 different sizes (type A, $2 \mathrm{~cm}^{2}$; type B, $6 \mathrm{~cm}^{2}$; and type $\mathrm{C}, 16.6 \mathrm{~cm}^{2}$ ) make 12 pressure stimuli as shown in Table 1 . The stimuli were given in a random order for subsequent statistical analysis. The sweating rates were measured by the electrohygrometric method on 19 female subjects sitting on a stool in a climate chamber of $36 \pm 1^{\circ} \mathrm{C}$ (dry bulb) and $34 \pm 1{ }^{\circ} \mathrm{C}$ (wet bulb). The effects of pressure stimuli were observed when the sweating rate was relatively stable in a range of $0.38-3.90 \mathrm{mg} / 20 \mathrm{~cm}^{2} \cdot \mathrm{min}$. The heart rate and rectal temperature were monitored throughout the experiments.

\section{RESULTS}

1. Spontaneous sweating of the symmetrical areas of the body

The sweating rates of the symmetrical areas of the body were measured by both methods. The sweat for $10 \mathrm{~min}$ on the upper and lower chest, and the back was measured 4 times in each of 8 experiments by the filter paper method. Between the paired areas the sweating rates differed by $20 \%$ on average, but they fluctuated mostly in parallel. Sweating rates on the left side of the lower chest, back and upper chest were plotted against those of the right side in Fig. $1 \mathrm{~A}, \mathrm{~B}$,
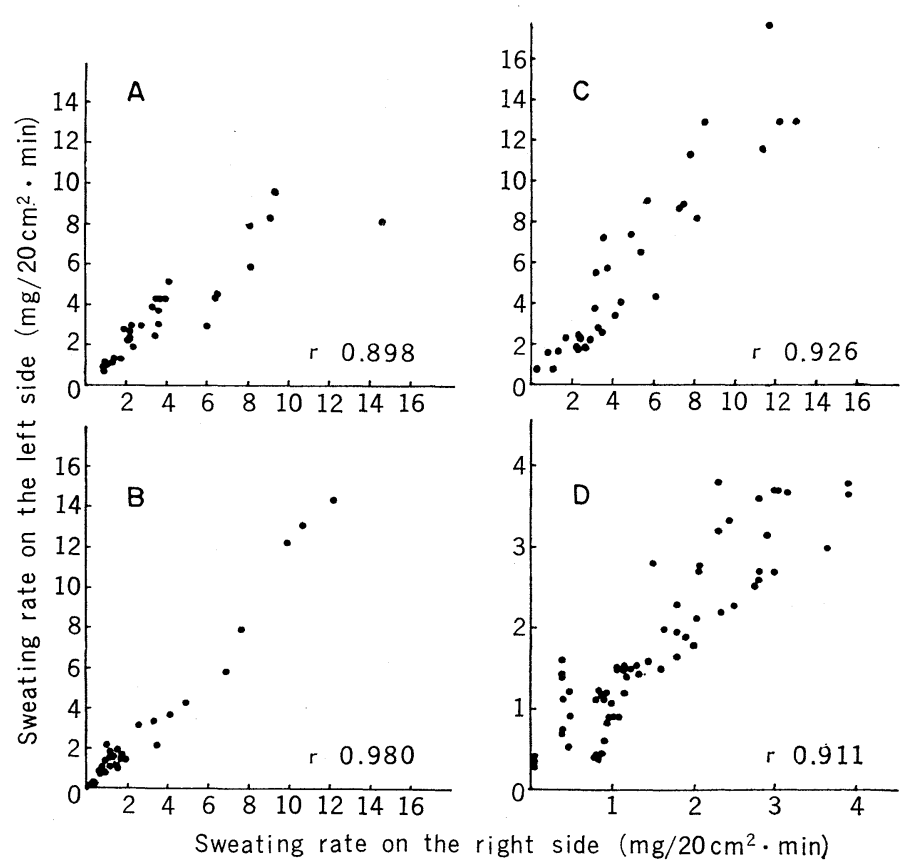

Fig. 1. The sweating rate simultaneously measured on symmetrical areas. The sweating rates on the left side are plotted against those on the right side. A (lower chest), B (back), and C (upper chest) were measured by the filter paper method. D (upper chest) was measured by the electrohygrometric method. 
and $\mathrm{C}$, respectively. Figure $1 \mathrm{D}$ similarly shows the sweating rates for $1 \mathrm{~min}$ on the upper chest measured by the electrohygrometric method in a different series of 18 experiments. The correlation coefficients of A, B, C, and D are 0.898 $(n=32), 0.980(n=32), 0.926(n=32)$, and $0.911(n=73)$, respectively. All of these values show highly significant correlation $(p \ll 0.001)$, indicating a considerable parallel change of the sweating in the symmetrical areas of the body surface.

\section{Pressure effects on sweating rate}

In 19 healthy women effects of pressure application on the sweating rates of symmetrical areas of the upper chest were studied by the electrohygrometric method. Unilateral pressure application consistently induced a reduction of the sweating rate on the side pressed as shown in Fig. 2a. Concomitant changes in the sweating rate of the opposite side were variable; a slight decrease, no apparent change, or a slight increase. As shown in Fig. $2 b$, changes in sweating rates during the stimulating period were measured for every $15 \mathrm{sec}\left(D_{15-60}, D_{15-60}^{\prime}\right)$. These values as well as the sweating rates before stimulation $\left(B, B^{\prime}\right)$ are expressed as $\mathrm{mg} / 20 \mathrm{~cm}^{2} \cdot \min$. The effect of pressure stimulation is represented as $\Delta S_{\mathrm{t}}=$ $\left(B-D_{t}\right)-\left(B^{\prime}-D^{\prime}{ }_{t}\right), t=15,30,45,60 \mathrm{sec}$ (see Fig. 2b).

Mean values of $\Delta S$ in 19 subjects obtained by applying weights of $1,2,3$, and $4 \mathrm{~kg}$ on disks of types A, B, and C are presented in Fig. 3. In most of the cases,

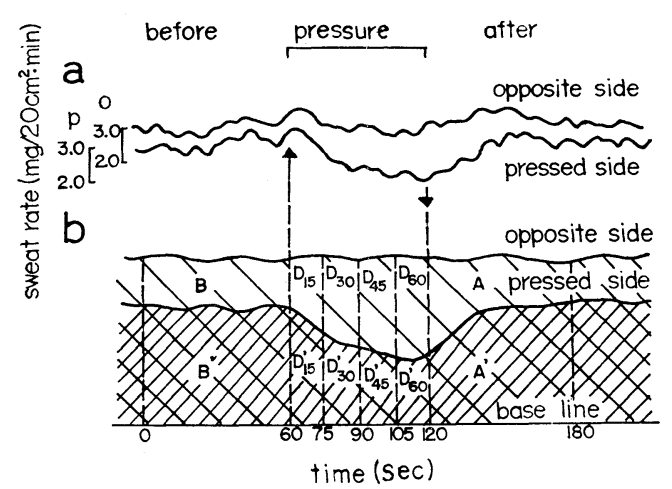

Fig. 2. Changes in the sweating rate produced by pressure application. a: traces of electrohygrometric recordings from the pressed side (lower trace) and the opposite side (upper trace). Pressure was given between two arrows. Scales of sweat rate for the opposite side (o) and the pressed side (p) are shown to the left. b: schematic drawing for measuring the change of sweating rate in pressure-stimulation experiments. $B, D$, and $A ; B^{\prime}, D^{\prime}$, and $A^{\prime}$ indicate the sweating rate before, during and after pressure application on the opposite side and the pressed side, respectively. The 1 min period of pressure application was divided into four and the sweating rate in each $15 \mathrm{sec}$ period $\left(D_{15-60}, D^{\prime}{ }_{15-60}\right)$ was measured and expressed in $\mathrm{mg} / 20 \mathrm{~cm}^{2} \cdot \mathrm{min}$. The net change in sweating rate produced by pressure stimulation is represented as $\Delta S_{15-60}=(B-$ $\left.D_{15-60}\right)-\left(B^{\prime}-D_{15-60}^{\prime}\right)$. 

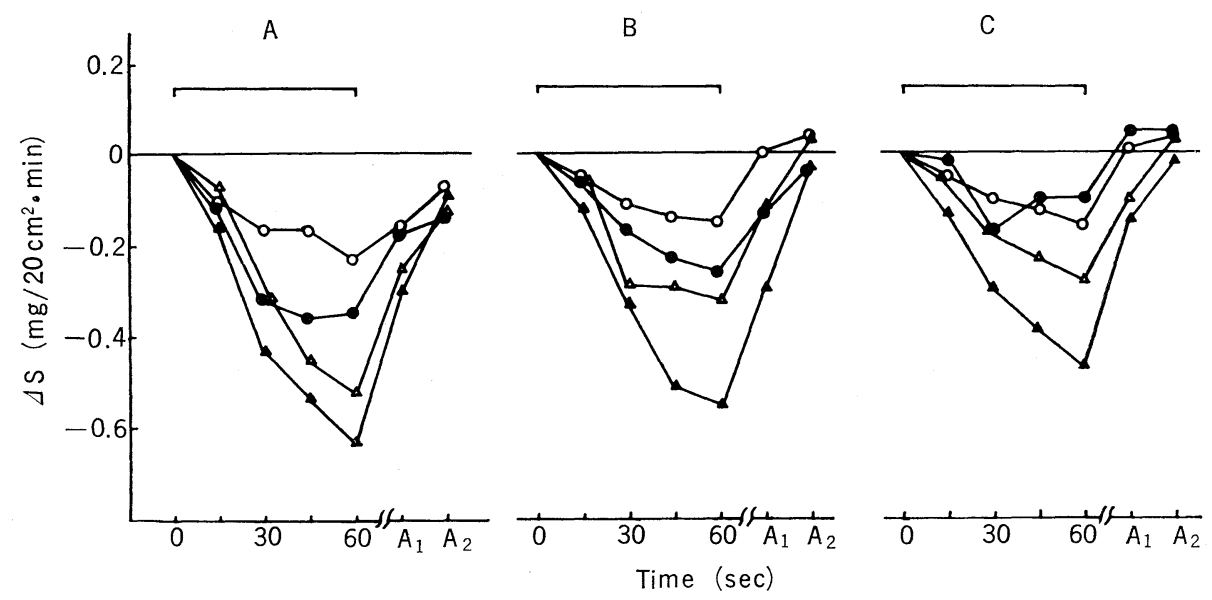

Fig. 3. Mean values of changes in sweating rate produced by unilateral pressure stimulaiton. The period of pressure application is indicated by a bar at the top. The effects of the weight of $1(0), 2(\bullet), 3(\Delta)$ and $4 \mathrm{~kg}(\Delta)$ applied on the disks with a surface area of 2, 6 and $16.6 \mathrm{~cm}^{2}$ are shown in $\mathrm{A}, \mathrm{B}$, and $\mathrm{C}$. The mean of $\Delta S$ in 19 subjects is plotted every $15 \mathrm{sec}$ during pressure stimulation and $1 \mathrm{~min}\left(\mathrm{~A}_{1}\right)$ and $3 \mathrm{~min}\left(\mathrm{~A}_{2}\right)$ after release of pressure.

the sweating rate began to decrease within $15 \mathrm{sec}$, and maximum reduction was observed in the last $15 \mathrm{sec}$. After releasing pressure, $\Delta S$ returned to the control value in a few minutes $\left(A_{1}, A_{2}\right.$ in Fig. 3). Since reductions of sweating rates in the last $15 \mathrm{sec}\left(\Delta S_{60}\right)$ were always statistically significant $(p<0.01)$, these values were used to evaluate the hemihidrotic effect. Values obtained with each of the three disks are plotted against the intensity of pressure $(P)\left(\mathrm{kg} / \mathrm{cm}^{2}\right)$. The regression equations calculated are:

$$
\begin{array}{ll}
\text { A: } & \Delta S_{60}=-0.2693 P-0.0985, \\
\text { B: } & \Delta S_{60}=-0.7347 P-0.0131, \\
\text { C: } & \Delta S_{60}=-1.8742 P+0.0294 .
\end{array}
$$

The regression lines thus obtained are shown in Fig. 4. There was a significant regression in each of the three lines $(p<0.001)$. Thus, it is established that the reduction of sweating in the side pressed is directly proportional to the pressure intensity per unit area in the three types of disks.

Furthermore, Fig. 4 reveals that the inclination of the regression lines of A, $\mathrm{B}$, and $\mathrm{C}$ increases in that order, corresponding to the increase in the surface area of pressure application. A larger inclination of the line indicates a larger inhibitory effect with the same intensity of pressure $\left(\mathrm{kg} / \mathrm{cm}^{2}\right)$. In Fig. 5 the inclination of the three regression lines are plotted against the surface areas of the disks used; both values are expressed as a ratio of those of $\mathrm{A}$. The degree of the inhibitory 


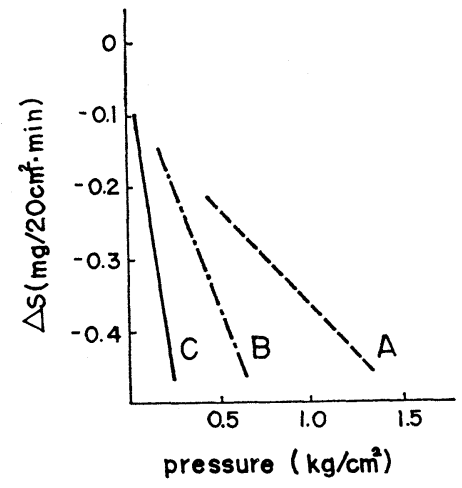

Fig. 4. Relationship between hemihidrotic effects and pressure intensity $\left(\mathrm{kg} / \mathrm{cm}^{2}\right)$. The regression lines were obtained from the plots of $76 \Delta S$-values during the last $15 \mathrm{sec}$ of pressure stimulation on each type of disk A (-----), B (-•-), and $\mathrm{C}(-)$ against pressure intensities.

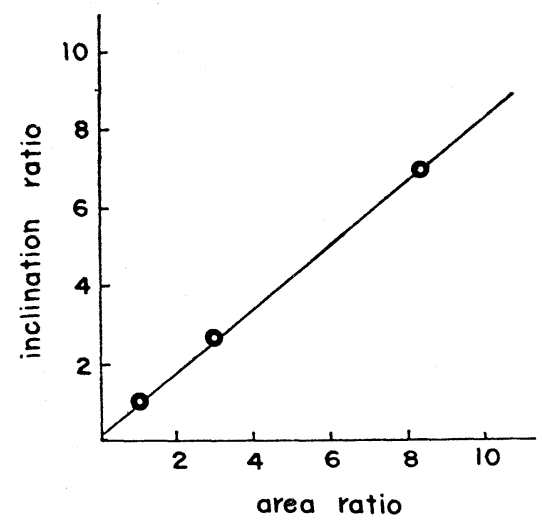

Fig. 5. Relationship between the inclination of the regression lines and the surface area of the disks. Both values are expressed as a ratio of the values obtained by disk $\mathrm{A}$.

effect is revealed to be directly proportional to the area of pressure application.

In Fig. 6, the hemihidrotic effect of pressure stimuli is illustrated in a different way: reductions of the sweating rates caused by unit area of the disks are plotted against the intensity of pressure $\left(\mathrm{kg} / \mathrm{cm}^{2}\right)$. The correlation coefficient between them is -0.9890 and is highly significant $(p \ll 0.001)$. This finding suggests that inhibition of sweating induced by the unit area of pressure stimulation is proportional to the intensity of pressure $\left(\mathrm{kg} / \mathrm{cm}^{2}\right)$. 


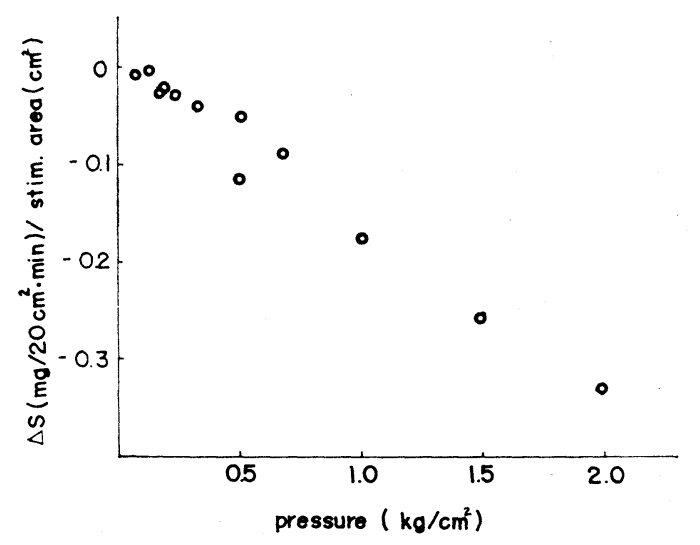

Fig. 6. Relationship between hemihidrosis caused by unit area of pressure stimulation and pressure intensity $\left(\mathrm{kg} / \mathrm{cm}^{2}\right)$.

\section{DISCUSSION}

It is well known that sweating of the human body shows regional differences (KUNO, 1934; WeINER, 1945), but little work has been done in regard to sweating of the symmetrical areas of the body. Rhythmic changes of sweating recorded by the electrohygrometric method were precisely coincident in the symmetrical areas of the chest (NAKAYAMA and TAKAGI, 1959).

By the filter paper method, WATKINS (1956) reported that sweating on the two sides of the body might fluctuate at random. Since rapid and large changes in sweating rates are frequently observed during electrohygrometric recording of sweating, a considerable error might be involved in the measurement by the filter paper method, unless sweating of the two sides is collected exactly at the same time. In the present experiment, therefore, every possible care was taken for an accurate and simultaneous collection of the paired filter papers. Correlation analysis on the sweat rates of the symmetrical areas of the upper and lower chest, and the back revealed a highly significant degree of association. Thus, Watkins' argument that hemihidrotic responses to pressure are spontaneous fluctuations in sweating observed by chance in the symmetrical areas on the body is strongly refuted. The sweating rates of the left and right side were not necessarily identical, but they differed by about $20 \%$ on average. Larger sweating rates in the dominant arm have been observed by Ogawa and his colleagues. This phenomenon is presumed to result from sweat gland trainings due to warming of the skin area by frequent usage of the underlying muscles (Ogawa, personal communication). Such peripheral factors might be involved in the present data, but the cause of this difference remains to be elucidated.

Using a centrifuge, FERres (1960) confirmed the finding of TAKAGI and 
SAKURAI (1950) that hemihidrosis induced by postural change was due to increase of pressure on the lateral side of the body. However, she could not observe this phenomenon when pressure was applied by pulling a broad band of cloth attached to the subaxillary region with a $5 \mathrm{~kg}$ weight. Though the exact contact area of this band with the skin surface is not known, the pressure on a unit area in her experiment is presumed to be close to, or below the threshold to cause this phenomenon. Generally, it is difficult to obtain consistent responses by weak stimuli close to threshold. In addition, pressure application to a large area might induce an uneven distribution of pressure and also might increase the possibility of involving regions with different threshold values, as is expected from the work by KAWASE (1952). These factors might disturb her in observing a consistent pressure-hemihidrosis.

It has been demonstrated that in addition to the hemihidrotic effect, skin pressure produces substantial effects on various body functions, such as autonomic functions, muscle tone, involuntary movements, consciousness etc. (TAKAGI and Kobayasi, 1955; NaKayama, 1957; Kumazawa, 1963; TaKagi, 1965; KosaKa et al., 1967; OGAwA et al., 1979). These works indicated that the responses were reflexly induced in the supraspinal or spinal level by afferent nervous signals activated by pressure stimulation, although the sensory receptors involved have not been identified.

The present study established quantitative relationships between the hemihidrotic effect and pressure stimulation. Regression analysis reveals with a high significance that the hemihidrotic effect is proportional to both the intensity of pressure per unit area and the surface area, at least within the experimental conditions employed in this study. Conceivably, the former relationship might be related to the number of impulses evoked in a receptor and the latter to the number of receptors activated.

The authors express their gratitude to Prof. Ohara, Nagoya City Univ. and Prof. Ogawa, Aichi Med. Univ., for reading the first draft of this paper and valuable comments on it.

\section{REFERENCES}

Ferres, H. M. (1960) The effect of pressure on sweating. J. Physiol. (Lond.), 151: 591-597.

KAwaSe, T. (1952) Further studies on "pressure sweat reflex." Jpn. J. Physiol., 3: 1-9.

KosaKa, M., TAKagi, K., and Koyama, M. (1967) Reflex inhibition of cold shivering by pressure in the skin and the histological investigation of its afferent spinal pathway. Experientia, 23: 453-455.

Kumazawa, T. (1963) "Deactivation" of the rabbit's brain by pressure application to the skin. EEG Clin. Neurophysiol., 15: 660-671.

Kuno, Y. (1934) The Physiology of Human Perspiration, Churchill, London.

NAKAYAMA, T. (1957) Behaviour of cervical muscles in labyrinthine and skin-pressure reflexes. Jpn. J. Physiol., 7: 99-112.

NAKAYAMA, T. and TAKAGI, K. (1959) Minute pattern of human perspiration observed by a continuously recording method. Jpn. J. Physiol., 9: 359-364. 
Ogawa, T., Asayama, M., Ito, M., and Yoshida, K. (1979) Significance of skin pressure in body heat balance. Jpn. J. Physiol., 29: 805-816.

Tadaki, E., Mizumura, K., Kumazawa, T., and Takagi, K. (1977) Reexamination of pressure hemihidrosis. Proc. Int. Union Physiol. Sci., 13: 738.

TAKAGI, K. (1965) Neural pathway of the skin pressure reflex. Saishin-Igaku, 20: 2018-2024 (in Japanese).

TAKagi, K. and SAKurai, T. (1950) A sweat reflex due to pressure on the body surface. Jpn. J. Physiol., 1: 22-28.

Takagi, K. and Kobayasi, S. (1955) Skin pressure-vegetative reflex. Acta Med. Biol., 4: 31-57.

Watkins, E.S. (1956) The effect on sweating of pressure on the body surface. $Q . J$. Exp. Physiol., 41: 263-270.

WeIner, J. S. (1945) The regional distribution of sweating. J. Physiol. (Lond.), 104: 32-40. 